\title{
Driving factors and spatiotemporal effects of environmental stress in urban agglomeration: Evidence from the Beijing-Tianjin-Hebei region of China
}

ZHOU Kan ${ }^{1,2}$, YIN Yue ${ }^{1,2}$, LI Hui ${ }^{3}$, SHEN Yuming ${ }^{3}$

1. Key Laboratory of Regional Sustainable Development Modeling, Institute of Geographic Sciences and Natural Resources Research, CAS, Beijing 100101, China;

2. College of Resources and Environment, University of Chinese Academy of Sciences, Beijing 100049, China;

3. College of Resource Environment and Tourism, Capital Normal University, Beijing 100048, China

\begin{abstract}
Environmental stress is used as an indicator of the overall pressure on regional environmental systems caused by the output of various pollutants as a result of human activities. Based on the pollutant emissions and socioeconomic databases of the counties in Beijing-Tianjin-Hebei region, this paper comprehensively calculates the environmental stress index (ESI) for the urban agglomeration using the entropy weight method (EWM) at the county scale and analyzes the spatiotemporal patterns and the differences among the four types of major functional zones (MFZ) for the period 2012-2016. In addition, the socioeconomic driving forces of environmental stress are quantitatively estimated using the geographically weighted regression (GWR) method based on the STIRPAT model framework. The results show that: (1) The level of environmental stress in the Beijing-Tianjin-Hebei region was significantly alleviated during that time period, with a decrease in ESI of $54.68 \%$ by 2016. This decrease was most significant in Beijing, Tangshan, Tianjin, Shijiazhuang, and other central urban areas, as well as the Binhai New Area. The level of environmental stress in counties decreased gradually from the central urban areas to the suburban areas, and the high-level stress counties were eliminated by 2016. (2) The spatial spillover effect of environmental stress increased further at the county scale from 2012 to 2016 , and spatial locking and path dependence emerged in the cities of Tangshan and Tianjin. (3) Urbanized zones (development-optimized and development-prioritized zones) were the major areas bearing environmental pollution in the Beijing-Tianjin-Hebei region in that time period. The ESI accounted for $65.98 \%$ of the whole region, where there was a need to focus on the prevention and control of environmental pollution. (4) The driving factors of environmental stress at the county scale included population size and the level of economic development. In addition, the technical capacity of environmental waste disposal, the intensity of agricultural production input, the intensity of territorial development, and the level of urbanization also had a certain
\end{abstract}

Received: 2020-09-20 Accepted: 2020-11-09

Foundation: National Natural Science Foundation of China, No.41971164, No.42071148; Strategic Priority Research Program of the Chinese Academy of Sciences, Grant No.XDA23020101

Author: Zhou Kan (1986-), PhD and Associate Professor, specialized in resources and environmental carrying capacity and regional sustainable development. E-mail: zhoukan@igsnrr.ac.cn

*Corresponding author: Shen Yuming (1968-), PhD and Professor, E-mail: shenyuming@263.net 
degree of influence. (5) There was spatial heterogeneity in the effects of the various driving factors on the level of environmental stress. Thus, it was necessary to adopt differentiated environmental governance and reduction countermeasures in respect of emission sources, according to the intensity and spatiotemporal differences in the driving forces in order to improve the accuracy and adaptability of environmental collaborative control in the Beijing-Tianjin-Hebei region.

Keywords: environmental stress; spatiotemporal effects; driving factors; urban agglomeration; major functional zones (MFZ); Beijing-Tianjin-Hebei region

\section{Introduction}

Urban agglomeration is usually accompanied by high levels of urbanization and industrialization, with large populations and large-scale economic activity, which is the essential spatial carrier promoting the main forms of urbanization and regional economic growth in China (Fang, 2014). However, driven by rapid urbanization and industrialization, high speed, high density and high intensity with inevitably lead to high energy consumption, high levels of industrial emissions and pollution problems, aggravating regional environmental pollution in areas of urban agglomeration, especially in the Beijing-Tianjin-Hebei region (Zhou et al., 2017; Zhou et al., 2019). For this reason, eco-environmental protection is regarded as a key area for setting priorities in "An Outline of Beijing-Tianjin-Hebei Collaborative Development Plan", which aims to curb the deteriorating trend in regional environmental quality and drastically reduce total emissions of major pollutants. At the same time, according to the positioning of the major functional zones (MFZ) in the region, the one province and two municipalities have successively implemented the negative list system for market access which clearly lists the sectors and fields off-limits for investors that do not meet environmental protection goals, and have increased pollution control and governance in the urban conurbation and surrounding areas since 2012, which allows for improving the detrimental effect of social and economic development on the environment.

Environmental stress is used as an indicator of the overall pressure on regional environmental systems caused by the output of various pollutants as a result of human activities. With the acceleration of industrialization and urbanization, the emission intensity and scale of pollutant emissions also increased rapidly, and disruption of the natural purification processes of environmental systems intensified, leading to reactions or symptoms such as structural imbalance, functional degradation, and even system collapse of the regional eco-environment (Barrett et al., 1976; Lazarus et al., 1997; Miao et al., 2001). Researchers both in China and abroad have carried out many studies on the changes resulting from environmental stress, its symptoms and driving forces in respect of emission intensity, emission reduction processes, and the main factors affecting different pollutants, providing a scientific basis for the maintenance of healthy environmental systems and the reconstruction of damaged ones.

In studies of the changes in the spatiotemporal patterns of environmental pollutants, single or multiple typical pollutant indicators are usually used, and the emission intensity of pollutants is measured and decomposed at the national (Leeuw et al., 2001; Liew et al., 2009; Lin et al., 2016; Rüttenauer, 2018; Shen et al., 2019), typical watershed (Zhang et al., 2011; Zou et al., 2016; Zhou et al., 2017), and provincial (Qu et al., 2006; Li et al., 2019) scales. 
These studies show that there are significant spatial differences and agglomeration characteristics in the emissions from major water bodies and of air pollutants, and the environmental stress pattern has a time-dependent path. As for studies of the driving factors of environmental stress, greater attention has been paid to the relationship between income level and environmental pollution in the early research. A large number of empirical studies have confirmed the existence of an environmental Kuznets curve (Dinda, 2004; Ma et al., 2006). The analysis of the driving factors has since been further extended to the socioeconomic and institutional fields by means of measurement models such as the logarithmic mean Divisia index (LMDI) method (Chen et al., 2015), the least square regression method (Zhou et al., 2016), panel model estimation (Kan, 2014; Wei et al., 2016), the decoupling index method (Wang et al., 2014), and the geographically weighted regression (GWR) model (Sun et al., 2017), which found the driving forces to be population and urbanization, industrial structure, investment level, technological progress, environmental protection investment, and environmental regulation. In recent years, in view of the spatial spillover characteristics of environmental stress, some researchers have used the spatial lag model (SLM) and the spatial error model (SEM) (Li et al., 2017), the Gaussian mixture model (GMM) (Yu et al., 2017), the mixed ordinary least squares (OLS) model (Xu et al., 2017), and other spatial econometric methods to investigate the effects of spatial factors and regional conduction on provincial environmental stress. In addition, empirical studies of the Beijing-Tianjin-Hebei region shows that the level of environmental stress is higher in plain areas and lower in mountainous areas, and there is also a spatial spillover effect among cities, especially in the level of atmospheric environmental stress that can be transmitted across regions (Zheng et al., 2014; Pan et al., 2015; Chen et al., 2016; Liu et al., 2018). A study of the driving factors also found that technological progress and industrial restructuring can alleviate the level of urban environmental stress in the Beijing-Tianjin-Hebei region (Ma et al., 2018), and the process of industrial transfer in Beijing will aggravate pollutant emissions and environmental stress in Hebei Province, where industrial development is the norm (Li et al., 2017; Wang et al., 2017).

Thus, while previous studies of environmental stress have focused mainly on the analysis of single factors, such as water or the atmosphere, quantitative evaluation of the overall level of regional environmental stress needs to be strengthened further. From the perspective of scale, most studies have focused on the macro level, such as the national, provincial, or urban scales, and more needs to be done at the micro scale. Reducing the basic research unit to the county scale tends to reflect the characteristics of the micro-location and the influence of the city center and suburbs, as well as the upstream and downstream regions of river basins and their tributaries. In addition, there are significant differences in the development modes and activities of different counties. Against a background of implementing the environmental policy of differentiated MFZ and the negative list system for market access at the county scale, analyzing environmental stresses and driving forces at the county scale is helpful for revealing the process of policy response and the mechanisms of environmental stress.

This paper, therefore, comprehensively calculates the environmental stress index (ESI) in the urban agglomeration of the Beijing-Tianjin-Hebei region using the entropy weight method (EWM) at the county scale and analyzes the spatiotemporal patterns of environ- 
mental stress and the differences among the four different types of MFZ between 2012 and 2016. The spatial spillover effect reflecting the spatial pattern analysis, the space-time evolution driving forces of environmental stress is quantitatively estimated by means of the GWR method based on the STIRPAT model framework in order to provide a reference for proposing improved regional environmental pollution prevention and control measures aimed at improving collaborative environmental management.

\section{Data and methods}

\subsection{Data sources and data processing}

The Beijing-Tianjin-Hebei region, lying between $36^{\circ} 05^{\prime} \mathrm{N}-42^{\circ} 40^{\prime} \mathrm{N}$ and $113^{\circ} 27^{\prime} \mathrm{E}-$ $119^{\circ} 50^{\prime} \mathrm{E}$, includes two municipalities under the direct jurisdiction of the central government, Beijing and Tianjin, and 11 prefecture-level cities in Hebei Province, with a total land area of $218,000 \mathrm{~km}^{2}$ (Figure 1). The topography of the northwest and north of the region is elevated, with mountains and plateaus forming the main kinds of terrain, while the southern and eastern regions are flat, with plains as the main kind of terrain. The Beijing-Tianjin-Hebei region is one of the most densely populated areas in China. At the end of 2016, the resident population totaled 112 million, accounting for $8.10 \%$ of the total population of China, with a gross domestic product (GDP) of 7521.4 billion yuan, accounting for $10.16 \%$ of national GDP, with a per capita GDP of 67,100 yuan, which was significantly higher than the national per capita GDP (53,700 yuan). In addition, the region is one of the most prominent urban agglomerations in China with major environmental problems. The region occupies $2.25 \%$ of the national land area and carries $5.75 \%$ of chemical oxygen demand (COD), $5.83 \%$ of ammonia nitrogen $\left(\mathrm{NH}_{3-\mathrm{N}}\right)$ emissions, $8.10 \%$ of sulfur dioxide $\left(\mathrm{SO}_{2}\right)$ emissions, and $5.61 \%$ of nitrogen oxide $\left(\mathrm{NO}_{x}\right)$ emissions. Environmental pollution has become a major obstacle to the sustainable and high-quality development of this urban agglomeration.

In this study, county was taken as the basic evaluation and research unit, and the datasets for $\mathrm{COD}, \mathrm{NH}_{3-\mathrm{N}}, \mathrm{SO}_{2}$, and $\mathrm{NO}_{x}$ in the Beijing-Tianjin-Hebei region for the period 2012-2016 were constructed, as well as the datasets for population and socioeconomic activity. The region had jurisdiction over 200 county (city, district) administrative units by the end of 2016. However, due to adjustments to administrative divisions, and taking into account the availability of data and the consistency of the statistics, the central urban areas with the same main functions as Beijing, including Dongcheng District, Xicheng District, Haidian District, Chaoyang District, Fengtai District, and Shijingshan District, were merged into one research unit, and the central urban areas in Tianjin and Hebei Province were also merged, which left 154 county-level research units.

In terms of data sources, the administrative boundary data were obtained from the website of the National Geomatics Center of China (http://www.ngcc.cn/ngcc/), and the pollutant emissions and socioeconomic data came mainly from the China County Statistical Yearbook, the Beijing Statistical Yearbook, the Tianjin Statistical Yearbook, the Hebei Economic Yearbook, and the statistical yearbooks of various prefecture-level cities in Hebei Province and the China Industrial Enterprise Database. Four types of MFZ (optimized development zone, 


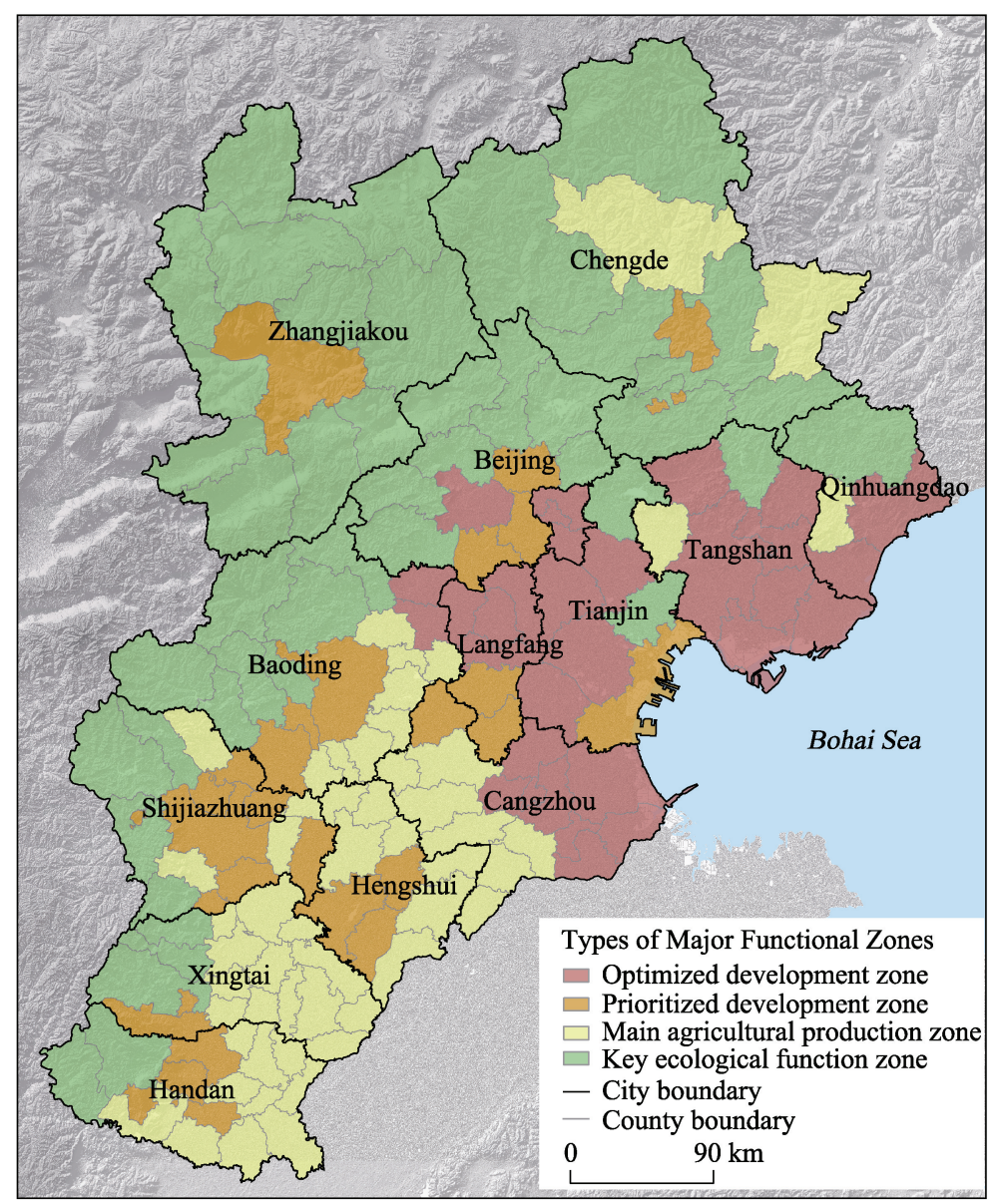

Figure 1 Distribution map showing the location of the Beijing-Tianjin-Hebei region the major functional zones (MFZ)

prioritized development zone, main agricultural production zone, and key ecological function zone) were derived from the National Major Functional Zone Planning and the provincial Major Functional Zone Planning of Beijing, Tianjin and Hebei Province (Figure 1).

\subsection{Research methods}

\subsubsection{Environmental stress index (ESI)}

The EWM was used to measure the ESI of counties in the Beijing-Tianjin-Hebei region. The EWM is an objective multi-index evaluation method for determining the index weight according to the original information of the evaluation index (Ou et al., 2008). The method is used for measuring the ESI, which comprises the following steps:

(1) Logarithmically transform the evaluation index:

$$
r_{i j}=\ln \left(a_{i j}\right)
$$

where $a_{i j}$ is the attribute value of class $j$ pollutants in county $i$, and $r_{i j}$ is the attribute value after natural logarithmic transformation. 
(2) Standardized transformation of evaluation index:

$$
r_{i j}^{\prime}=\frac{r_{i j}-\min \left\{r_{i j}\right\}}{\max \left\{r_{i j}\right\}-\min \left\{r_{i j}\right\}}
$$

where $r_{i j}$ is the attribute value of class $j$ pollutants in county $i(i=1,2, \ldots, n ; j=1,2, \ldots, m)$, and $r_{i j}^{\prime}$ is the property value after range standardization. The values of $\max \left\{r_{i j}\right\}$ and $\min \left\{r_{i j}\right\}$ are the maximum and minimum values of the attribute values of class $j$ pollutants in county $i$, respectively.

(3) Calculate the specific gravity $R_{i j}$ of class $j$ pollutants in county $i$ :

$$
R_{i j}=\frac{r_{i j}^{\prime}}{\sum_{i=1}^{n} r_{i j}^{\prime}}
$$

(4) Calculate the entropy weight $E_{j}$ of the class $j$ pollutant index:

$$
E_{j}=-\frac{1}{\ln (n)} \sum_{i=1}^{n} R_{i j} \ln \left(R_{i j}\right)
$$

(5) Calculate the information utility value $G_{j}$ of the class $j$ pollutant index:

$$
G_{j}=1-E_{j}
$$

(6) Calculate the weight $W_{j}$ of the class $j$ pollutant index:

$$
W_{j}=\frac{G_{j}}{\sum_{j=1}^{m} G_{j}}
$$

(7) Calculate the environmental pollution stress index $\operatorname{EPSI}_{i}$ in county $i$ :

$$
\operatorname{EPSI}_{i}=\sum_{j=1}^{m} W_{j} r_{i j}^{\prime}
$$

where the value of $E P S I_{i}$ reflects the comprehensive level of stress in each county unit for each pollutant. The larger the $E P S I_{i}$ value, the higher the intensity of pollution emissions and the greater the pressure faced by water bodies and the atmosphere, which means a greater level of environmental stress suffered by each county.

\subsubsection{GWR model}

GWR was used to analyze the driving forces of environmental stress in the counties of the Beijing-Tianjin-Hebei region and explore the spatial heterogeneity of these driving forces in different regions (Brunsdon et al., 1996). This embeds geographic location information into the regression parameters, allowing spatial heterogeneity of the regression coefficients, which is an effective method for investigating spatial non-stationarity. The following is the basic model:

$$
y_{i}=\beta_{0}\left(u_{i}, v_{i}\right)+\sum_{k=1}^{m} \beta_{k}\left(u_{i}, v_{i}\right) x_{i k}+\varepsilon_{i}
$$

where $\left(u_{i}, v_{i}\right)$ are the geographical coordinates of county $i$ in the Beijing-Tianjin-Hebei region and $\beta_{k}\left(u_{i}, v_{i}\right)$ is the regression parameter of the $k$ explanatory variable of county $i$. The variable $\beta_{0}\left(u_{i}, v_{i}\right)$ is the constant term, the value of $m$ is the number of explanatory variables, 
and $\varepsilon_{i}$ is the random error. The regression coefficient $\beta_{k}\left(u_{i}, v_{i}\right)$ of the GWR model is expressed as:

$$
\beta_{k}\left(u_{i}, v_{i}\right)=\left(X^{T} W\left(u_{i}, v_{i}\right) X\right)^{-1} X^{T} W\left(u_{i}, v_{i}\right) y_{i}
$$

where $y_{i}$ is the county $E P S I_{i}$, which is the interpreted variable, $X$ is the matrix of explanatory variable, and $X^{T}$ is its transpose matrix; the variable $W\left(u_{i}, v_{i}\right)$ is the spatial weight matrix of observation point $i$.

In terms of the research experience of STIRPAT model setting and factor selection (Li et al., 2011; Yan et al., 2010), taking into account the availability and representativeness of county-level administrative district data, the corresponding indicators were selected as explanatory variables with respect to population size, economic development level, industrialization level, land development intensity, environmental treatment technology level, urbanization level, and agricultural production input intensity. The final set model is as follows:

$$
\begin{aligned}
E S I_{i}= & \beta_{0}\left(u_{i}, v_{i}\right)+\sum_{k=1}^{m}\left(T P_{i}\right)\left(u_{i}, v_{i}\right) x_{i k}+\sum_{k=1}^{m}\left(P G D P_{i}\right)\left(u_{i}, v_{i}\right) x_{i k}+ \\
& \sum_{k=1}^{m}\left(I S_{i}\right)\left(u_{i}, v_{i}\right) x_{i k}+\sum_{k=1}^{m}\left(T D I_{i}\right)\left(u_{i}, v_{i}\right) x_{i k}+ \\
& \sum_{k=1}^{m}\left(E T T_{i}\right)\left(u_{i}, v_{i}\right) x_{i k}+\sum_{k=1}^{m}\left(U R_{i}\right)\left(u_{i}, v_{i}\right) x_{i k}+ \\
& \sum_{k=1}^{m}\left(I A P_{i}\right)\left(u_{i}, v_{i}\right) x_{i k}+\varepsilon_{i}
\end{aligned}
$$

where $T P_{i}$ is the resident population at the end of the year (in multiples of 10,000 people), reflecting the population size of the county; $P G D P_{i}$ is the per capita GDP (yuan/person), reflecting the level of county economic development; $I S_{i}$ is the proportion of the added value of the secondary industry to GDP (\%), reflecting the level of industrialization of the county; and $T D I_{i}$ is the proportion of construction land to the total land area of the county (\%), which reflects the intensity of county land development. Because it was difficult to obtain the county environmental technical indicators directly, the county environmental treatment technical level can be reflected through the substitution of pollution intensity per unit GDP $\left(E T T_{i}\right)$ by referring to relevant studies (Huang et al., 2012). $U R_{i}$ is the urbanization rate, which reflects the urbanization level of the county; and $I A P_{i}$ is the input intensity of agricultural production, which is calculated from the total power usage of all agricultural machinery and the quantity of chemical fertilizers used (Li et al., 2011; Li et al., 2019).

\section{Results and analysis}

\subsection{Spatiotemporal effects of environmental stress experienced by counties in the Beijing-Tianjin-Hebei region}

\subsubsection{Evolution characteristics of county-scale environmental stress}

EWM was used to measure the county-scale ESI, which was divided into five grades: low, lower, general, higher, and high, by means of the Jenks natural breaking point method. The 
results are presented in Table 1 and Figure 2. The following are the evolution characteristics of the county environmental stress in the Beijing-Tianjin-Hebei region for the period 2012-2016.

The level of environmental stress faced by the Beijing-Tianjin-Hebei region was significantly alleviated between 2012 and 2016, and the average county-scale ESI of dropped from 0.084 in 2012 to 0.038 in 2016 , a decrease of $54.68 \%$. The sharp decline in the level of environmental stress reflects a series of powerful environmental regulation events, such as the implementation of the Action Plan for Air Pollution Prevention and Control (Ten Articles for Atmospheric Countries) and the Action Plan for Water Pollution Prevention and Control (Ten Articles for Water Countries), as well as the successive deployment of pollution control plans for key industries in Beijing-Tianjin-Hebei and surrounding areas and the detailed rules for regional air and water pollution reduction, all of which played a role in curbing the intensity of pollutant emissions at the county scale. Compared with 2012, COD and emissions of $\mathrm{NH}_{3-\mathrm{N}}, \mathrm{SO}_{2}$, and $\mathrm{NO}_{x}$ in the region decreased by $65.9 \%, 47.2 \%, 46.2 \%$, and $50.8 \%$, respectively, by 2016. The level of environmental stress decreased most significantly in the counties of Beijing, and the ESI there decreased by $63.35 \%$, which was greater than that of Tianjin (57.75\%) and Hebei (53.07\%).

Table 1 Emission intensity and ESI in the Beijing-Tianjin-Hebei region in 2012 and 2016

\begin{tabular}{|c|c|c|c|c|c|c|c|c|c|c|}
\hline \multirow{2}{*}{ Area } & \multicolumn{5}{|c|}{2012} & \multicolumn{5}{|c|}{2016} \\
\hline & $\operatorname{COD}(\mathrm{t})$ & $\mathrm{NH}_{3-\mathrm{N}}(\mathrm{t})$ & $\mathrm{SO}_{2}(\mathrm{t})$ & $\mathrm{NO}_{x}(\mathrm{t})$ & ESI & $\operatorname{COD}(\mathrm{t})$ & $\mathrm{NH}_{3-\mathrm{N}}(\mathrm{t})$ & $\mathrm{SO}_{2}(\mathrm{t})$ & $\mathrm{NO}_{x}(\mathrm{t})$ & ESI \\
\hline Beijing & 16954.62 & 1862.13 & 8531.76 & 8876.63 & 0.10 & 7917.70 & 506.92 & 3019.09 & 3191.49 & 0.04 \\
\hline Tianjin & 32776.27 & 3630.82 & 32074.49 & 40024.72 & 0.28 & 14753.91 & 2235.31 & 10087.73 & 13820.09 & 0.12 \\
\hline Hebei & 9933.54 & 814.72 & 9871.90 & 8921.88 & 0.07 & 3023.46 & 451.93 & 5804.73 & 4786.54 & 0.03 \\
\hline $\begin{array}{l}\text { Beijing- } \\
\text { Tianjin- } \\
\text { Hebei region }\end{array}$ & 11473.35 & 1017.54 & 10785.39 & 10332.41 & 0.08 & 3906.25 & 536.92 & 5800.44 & 5083.22 & 0.04 \\
\hline
\end{tabular}

Between 2012 and 2016, the level of environmental stress in the counties of the Beijing-Tianjin-Hebei region decreased as a whole, especially in the high-grade area of the ESI, which is mainly in the central city region. From 2012, the high-scale counties suffering environmental stress included Tangshan, Tianjin, Shijiazhuang, Beijing, and the Handan and Tianjin Binhai New Area, which are distributed mainly around the Bohai Rim and along the Beijing-Guangzhou Railway line. The ESI of such counties accounted for $28.57 \%$ of the total in the Beijing-Tianjin-Hebei region, which bore nearly $30 \%$ of the pollution discharge pressure. Higher-grade counties included Zhangjiakou, Baoding, Qinhuangdao, and Chengde, as well as Qian'an, the Caofeidian area, Jizhou, Wu'an, Pingshan, and Dingzhou, which are located mainly in the northern prefecture-level city center and the periphery of high-grade areas. The counties suffering high-grade environmental stress were no longer doing so by 2016, and the number of higher-grade counties dropped from 10 to 6 , which are located in the coastal areas of Tianjin and Tangshan in the east and Shijiazhuang and Handan in the south. The counties with lower levels of environmental stress are distributed mainly around the higher- and general-grade areas, including 15 county units such as Caofeidian, Shahe, Luanxian, and the municipal districts of Zhangjiakou and Qinhuangdao. The area of low-grade counties accounted for more than $80 \%$ of the total area, and the county-scale ESI 
accounted for $18.20 \%$ of the total, which bore only about $20 \%$ of the pollution discharge pressure in the Beijing-Tianjin-Hebei region. Further analysis found that the ESI in the Beijing-Tianjin-Hebei region gradually decreased with distance from the central city, and the level of environmental stress formed a core and peripheral structure that gradually decreased from the center of the city to the periphery.
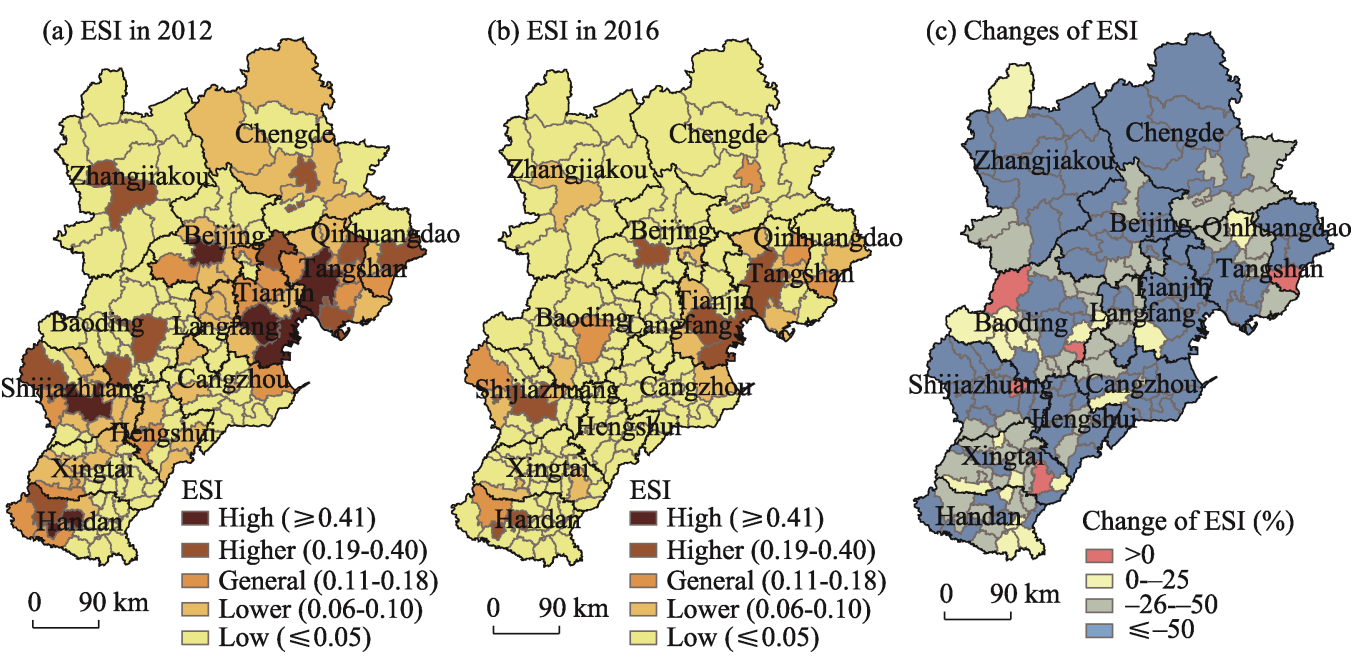

Figure 2 ESI and its spatial changes in the Beijing-Tianjin-Hebei region in 2012 and 2016

The changes in the county-scale ESI between 2012 and 2016 were calculated and found to be $0 \%$ to $-25 \%,-26 \%$ to $-50 \%$, less than $-50 \%$, and areas with an increasing stress index were greater than $0 \%$. The results are shown in Figure 2c. Between 2012 and 2016, there were 149 counties with a reduced ESI, of which 83 counties showed a decrease of more than $50 \%$, accounting for $65.31 \%$ of the total land area, including Beijing, Tianjin, Chengde, Shijiazhuang, and Zhangjiakou. There were 47 counties with a decrease of $26 \%-50 \%$, accounting for $23.18 \%$ of the total land area, mainly in Handan, Xingtai, Cangzhou, Baoding, and Chengde. It should be pointed out that there were still counties with an increasing ESI in partial areas in 2016, including Weixian, Laiyuan, Gaoyang, Changli, and Wuji. These counties are located in the border areas of the administrative boundaries of cities and are usually areas with weak environmental regulation and control.

\subsubsection{County-scale spatial effects of environmental stress}

The global Moran's I values of the ESI in counties for major pollutant emissions are listed in Table 2. The estimated values of Moran's I from 2012 to 2016 were all greater than 0 and passed the $95 \%$ significance test, indicating that there was a significant spatial correlation between environmental stress and pollutant emissions in the county units of the Beijing-Tianjin-Hebei region for that period. The Moran's I value of the county-scale ESI increased from 0.2014 in 2012 to 0.2325 in 2016, which shows that the spatial spillover effect of environmental stress increased, and the areas experiencing high- or low-grade stress were more spatially concentrated in 2016. According to the decomposition of pollutant emissions, the Moran's I index of $\mathrm{NH}_{3-\mathrm{N}}$ and $\mathrm{NO}_{x}$ emissions also increased significantly, while the Moran's I index of COD decreased from 0.1666 in 2012 to 0.1309 in 2016, and that of $\mathrm{SO}_{2}$ 
emissions decreased from 0.2186 in 2012 to 0.1865 in 2016 . In order to further analyze the spatial correlation characteristics of county-scale environmental stress, the Getis-Ord G* index of county-scale ESI in 2012 and 2016 was calculated. The G* index was then divided into four types, from high to low, namely, hot spot area, sub-hot spot area, sub-cold spot area, and cold spot area, and a graph of the changes in local spatial correlation was generated. As shown in Figure 3, on the whole, the heat map of county-scale ESI basically decreased continuously from coastal to inland areas, and that of county units around the Bohai Rim were significantly higher than those of inland counties. The coastal cities of Tianjin and Tangshan had been hot spots for a long time, showing strong spatial locking and path dependence.

Table 2 Moran's I of ESI and major pollutants in the Beijing-Tianjin-Hebei region

\begin{tabular}{lcccccccc}
\hline \multirow{2}{*}{ Indicator } & \multicolumn{3}{c}{2012} & & \multicolumn{3}{c}{2016} \\
\cline { 2 - 3 } \cline { 6 - 8 } & Moran's $I$ & $z$-score & $p$-value & & Moran's $I$ & $z$-score & $p$-value \\
\hline COD & 0.1666 & 3.6114 & 0.0003 & & 0.1309 & 2.9777 & 0.0029 \\
$\mathrm{NH}_{3-\mathrm{N}}$ & 0.1592 & 3.6328 & 0.0003 & & 0.1933 & 4.4142 & 0.0000 \\
$\mathrm{SO}_{2}$ & 0.2186 & 4.8671 & 0.0000 & & 0.1865 & 4.1760 & 0.0000 \\
$\mathrm{NO}_{x}$ & 0.1847 & 4.0896 & 0.0000 & & 0.2720 & 5.9211 & 0.0000 \\
ESI & 0.2014 & 4.3945 & 0.0000 & & 0.2325 & 5.0628 & 0.0000 \\
\hline
\end{tabular}

In terms of the hot spot map for 2012 (Figure 3a), the hot spot areas include Tianjin and Tangshan and 13 county units, including Binhai New Area, Caofeidian, Luannan, and Laoting, which basically cover the whole Tianjin and Tangshan area. Sub-hot spots include the periphery of hot spot areas and 23 county units, including Cixian, Shexian, Wu'an, Pingshan, Lingshou, and Huailai, which are concentrated around northern coastal cities such as Tianjin, Tangshan, and Qinhuangdao and scattered in the western mountainous areas of Hebei. By 2016 (Figure 3b), the number of hot spots had increased slightly to 14, among which Qianxi and Shexian changed from being sub-hot spots to hot spots and Wuqing changed to a sub-hot spot. The hot spot areas were basically stable, and the southwest of the Beijing-TianjinHebei region began to show high-value areas. The number of sub-hot spots had fallen to 21 by 2016 , and all counties under the jurisdiction of Beijing were no longer sub-hot spot areas. The average value of ESI in the hot spot areas decreased from 0.26 in 2012 to 0.12 in 2016 and that of the sub-hot spot areas decreased from 0.11 to 0.06 over the same period, which indicated that although the pattern of concentration of environmental stress in the Beijing-Tianjin-Hebei region remained unchanged, overall mitigation of environmental stress could still be achieved through coordinated emission reduction policies and control of regional environmental pollutants. The cold spot areas of ESI were located in Hebei Province in 2012, distributed mainly in Baoding, Cangzhou, Hengshui, and Xingtai, with a total of 58 county units. The sub-cold spot areas were mainly in the northern part of Beijing, Tianjin, and Hebei and in the central and western regions, covering Chengde, Beijing, and Shijiazhuang. By 2016, the total number of cold spots in the ESI remained unchanged, and the low-value agglomeration area extended to the northwest of the Beijing-Tianjin-Hebei region, which meant that the counties under Zhangjiakou in Hebei and Miyun District in Beijing became cold spot areas.

3.1.3 Environmental stress characteristics of various major functional zones

The ESI of various types of MFZ was decomposed according to the optimized de- 

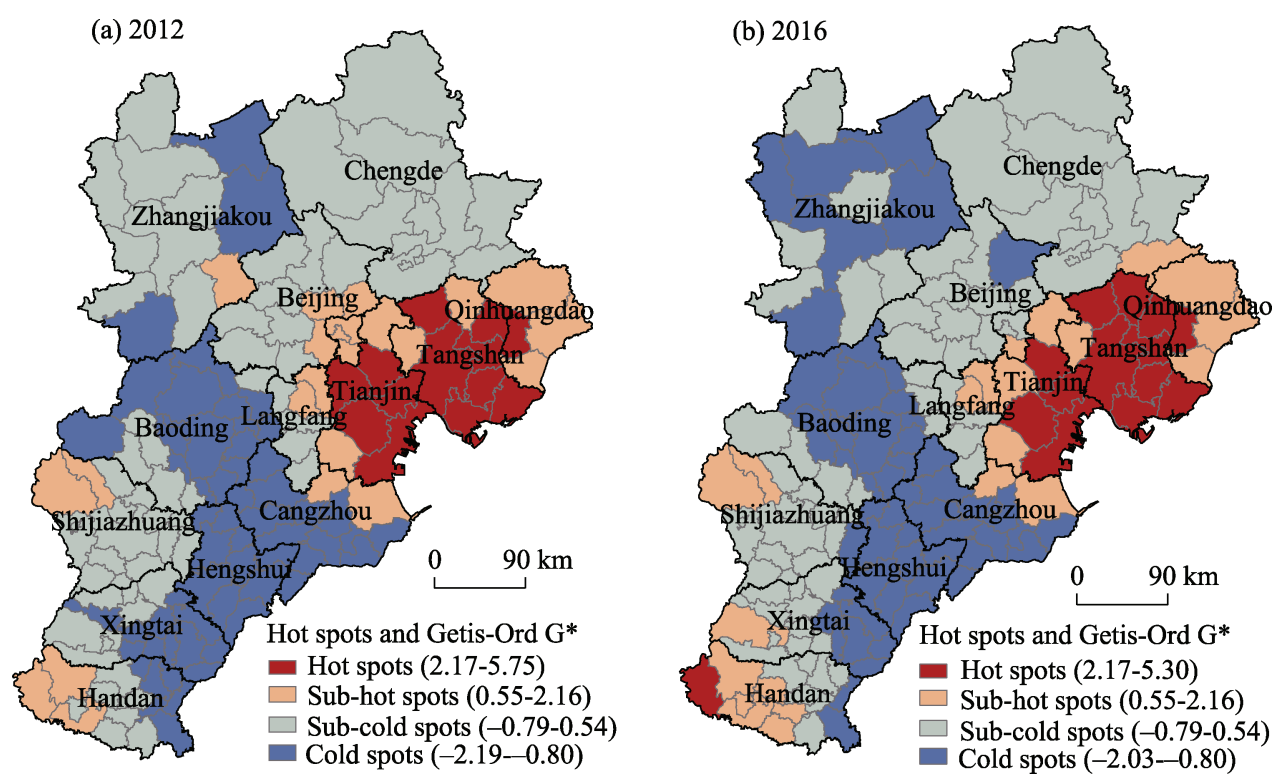

Figure 3 Spatial changes in ESI in cold and hot spots in the Beijing-Tianjin-Hebei region in 2012 and 2016

velopment, prioritized development, main agricultural production, and key ecological function zones. As shown in Figure 4, the level of environmental stress in the two types of urbanized areas was significantly higher than that in the restricted development areas, which are the main pressure-bearing areas for environmental pollutant emissions in the Beijing-Tianjin- Hebei region. In 2016, the average value of the ESI in the prioritized development zone was 0.0683 , which was slightly higher than that in optimized development zones (0.0677), 2.72 times that in the key ecological function zones, and 3.93 times that in main agricultural production zone. Moreover, the ESI of the optimized development and prioritized development zones accounted for $65.98 \%$ of the total urban agglomeration. The urbanized area bore more than $60 \%$ of the pollutant discharge pressure, which was the main environmental stress area of the Beijing-Tianjin-Hebei region. However, the main agricultural production zones and key ecological function zones accounted for only $15.60 \%$ and $18.42 \%$, respectively.

Comparing the mean values of the stress index over the five-year period, we found that the ESI of various types of MFZ in the Beijing-Tianjin-Hebei region decreased by more than $50 \%$, with the largest decrease being in the key ecological function zones. The average value of the ESI decreased by $56.51 \%$, compared with 2012, and the smallest decrease of $50.94 \%$ occurred in the main agricultural production zones. The urban conglomeration is still the main pressure-bearing area for environmental pollutant discharge, and the optimized development and prioritized development zones are still the foci of environmental pollution prevention and control in the Beijing-Tianjin-Hebei region. In terms of provinces and cities, the ESI of the optimized development, prioritized development, and key ecological function zones in Beijing decreased by $64.84 \%, 61.51 \%$, and $62.32 \%$, respectively, which is the most prominent province and city in the Beijing-Tianjin-Hebei region, and against the background of coordinated development of Beijing-Tianjin-Hebei, Beijing's non-capital function relief has brought more obvious improvement to its own level of environmental stress. 


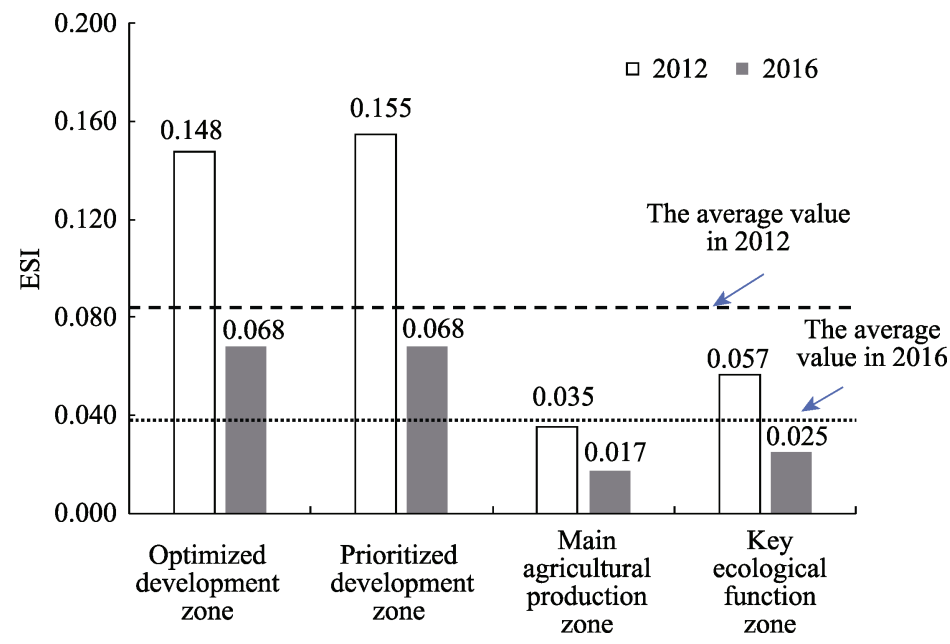

Figure 4 The ESI of major functional zones in the Beijing-Tianjin-Hebei region in 2012 and 2016

\subsection{Driving factors of environmental stress in counties of the Beijing-Tianjin-Hebei region}

\subsubsection{Model testing}

Before executing the GWR model, global OLS regression was performed in order to compare the goodness of fit. The results (Table 3) show that the test results of K(BP) statistics pass the $99 \%$ significance test, demonstrating that the model has statistically significant heteroscedasticity (non-stationarity), and it is necessary to use chi-square statistics to evaluate the statistical significance of the explanatory variables. The joint chi-square statistics pass the $99 \%$ significance test, that is, all explanatory variables have a certain explanatory power in the model. The variance inflation factor (VIF) is less than 7.5, and there is no redundancy or multicollinearity in the variables. The Jarque-Bera test results pass the $99 \%$ significance

Table 3 Estimated results of the OLS model in the Beijing-Tianjin-Hebei region

\begin{tabular}{|c|c|c|c|c|c|c|c|c|c|c|}
\hline \multirow[b]{2}{*}{ Variable } & \multicolumn{5}{|c|}{2012} & \multicolumn{5}{|c|}{2016} \\
\hline & Coefficient & $\begin{array}{l}\text { Standard } \\
\text { error }\end{array}$ & $T$ statistic & $P$ value & VIF & $\begin{array}{c}\text { Coeffi- } \\
\text { cient }\end{array}$ & $\begin{array}{l}\text { Stan- } \\
\text { dard } \\
\text { error }\end{array}$ & $T$ statistic & $P$ value & VIF \\
\hline Intercept & $-0.1521^{* *}$ & 0.0200 & -7.5971 & 0.0000 & - & $-0.1939^{* *}$ & 0.0232 & -8.3752 & 0.0000 & - \\
\hline$T P$ & $0.8183^{* *}$ & 0.0691 & 11.8378 & 0.0000 & 1.9735 & $0.6341^{* *}$ & 0.0764 & 8.2948 & 0.0000 & 2.0188 \\
\hline$P G D P$ & $0.7390^{* *}$ & 0.0684 & 10.8029 & 0.0000 & 1.4166 & $0.6220^{* *}$ & 0.0764 & 8.1423 & 0.0000 & 1.3983 \\
\hline$I S$ & 0.0413 & 0.0277 & 1.4900 & 0.1062 & 1.1709 & $0.0763^{*}$ & 0.0324 & 2.3520 & 0.0034 & 1.2015 \\
\hline$T D I$ & $-0.1650^{* *}$ & 0.0498 & -3.3139 & 0.0044 & 2.4017 & $-0.1347^{* *}$ & 0.0543 & -2.4799 & 0.0131 & 2.3414 \\
\hline ETT & $0.3260^{* *}$ & 0.0351 & 9.2818 & 0.0000 & 1.0524 & $0.3028^{* *}$ & 0.0319 & 9.4878 & 0.0000 & 1.0906 \\
\hline$U R$ & $0.2135^{* *}$ & 0.0346 & 6.1780 & 0.0001 & 2.0578 & $0.2630^{* *}$ & 0.0378 & 6.9495 & 0.0001 & 2.0217 \\
\hline$I A P$ & $0.2802^{* *}$ & 0.0326 & 8.5851 & 0.0002 & 1.0872 & $0.2515^{* *}$ & 0.0349 & 7.1992 & 0.0007 & 1.1159 \\
\hline \multirow[t]{2}{*}{$\begin{array}{l}\text { Model } \\
\text { diagnosis }\end{array}$} & $\begin{array}{l}\text { Chi-square } \\
\text { statistics }\end{array}$ & $\begin{array}{l}\text { Correc- } \\
\text { tion } R^{2}\end{array}$ & AIC & $\begin{array}{c}\mathrm{K}(\mathrm{BP}) \\
\text { test }\end{array}$ & $\begin{array}{l}\text { Jarque-- } \\
\text { Bera test }\end{array}$ & $\begin{array}{l}\text { Chi-squar } \\
\text { e statistics }\end{array}$ & $\begin{array}{c}\text { Cor- } \\
\text { rection } \\
R^{2}\end{array}$ & AIC & $\begin{array}{c}\mathrm{K}(\mathrm{BP}) \\
\text { test }\end{array}$ & $\begin{array}{l}\text { Jarque-- } \\
\text { Bera test }\end{array}$ \\
\hline & 1277.1215 & 0.8469 & -411.5215 & $33.50139^{* *}$ & $3816.7202^{* *}$ & 996.9724 & 0.7847 & -376.3448 & $31.2104^{* *}$ & $3411.6170^{* *}$ \\
\hline
\end{tabular}

Note: $* *$ is significant at the 0.01 level and * is significant at the 0.05 level. 
test, and the regression coefficient residuals are not normally distributed. The determinable coefficient $R^{2}$ shows that OLS regression can explain only about $80 \%$ of the ESI, and the variables have spatial heterogeneity, so the GWR model should be introduced for analysis. In the GWR model, the central latitude and longitude of county units are taken as geographical coordinates, the fixed distance method is selected to determine the fixed Gaussian kernel function, and the Akaike minimum information criterion (AIC) is used to determine the optimal bandwidth. The fitted results are listed in Table 4: the AIC value of the GWR model is significantly smaller than that of the OLS model, and the corrected $R^{2}$ values are increased by $11.89 \%$ and $14.74 \%$ compared with that of the OLS model, reflecting the fact that the GWR model is better at investigating the spatial heterogeneity of causative factors.

\subsubsection{Analysis of causative factors and spatial heterogeneity}

The estimated results of the OLS model show that during 2012-2016, the significant positive driving factors for county-scale environmental stress in the Beijing-Tianjin-Hebei region were population size, economic development level, environmental treatment technology level, agricultural production input intensity, and urbanization level. In 2012, each 1\% increase in population size increased the ESI by $0.8183 \%$ and each $1 \%$ increase in economic development level increased the ESI by $0.7390 \%$. The ESI increased by $0.3260 \%$ for a $1 \%$ increase in the level of environmental treatment technology characterized by the pollution intensity index per unit GDP. The ESI increased by $0.2802 \%$ for a $1 \%$ increase in agricultural production input intensity. In addition, each $1 \%$ increase in urbanization level increased the ESI by $0.2135 \%$. From the perspective of these changes, the driving intensity of population size and economic development level decreased significantly. In 2016, the elastic coefficient of population size decreased by $22.51 \%$, and the elastic coefficient of economic development level factors decreased by $15.83 \%$. The driving intensity of environmental treatment technology level remained at about $0.3 \%$, which reflected the fact that improvements in environmental treatment technology contributed to cleaner production lifestyles in the counties, thus reducing the intensity of pollution emissions and alleviating environmental stress.

In 2016, the regression coefficient of industrialization also passed the $95 \%$ significance test, indicating that the increase in the proportion of industry in the industrial structure began to show the pull of county environmental stress. Each $1 \%$ increase in the proportion of industry increased the ESI by $0.0763 \%$. The importance of the level of urbanization increased in 2016, which exceeded that of agricultural production input intensity. In addition, the intensity of land development played a significant negative role, and each $1 \%$ increase in the intensity of land development reduced the ESI by $0.13 \%-0.17 \%$. As listed in Table 4 , the average value of the regression coefficients estimated by the GWR model reflects the marginal contribution of different factors (Sha, 2016), and the effect of each factor is basically consistent with the estimated results of the OLS model. After generating the spatial distribution map of the regression coefficients of the GWR model (Figure 5), the spatial heterogeneity of each driving factor presents the following characteristics.

(1) The regression coefficient of population size was positive in the Beijing-TianjinHebei region, and the increase in population size significantly increased the level of environmental stress in the counties. The impact of population size on county-scale environmental stress decreased from the southwest and northeast to the central and western regions 
Table 4 Estimated results of the GWR model for the Beijing-Tianjin-Hebei region

\begin{tabular}{|c|c|c|c|c|c|c|c|c|c|c|c|c|}
\hline \multirow[b]{2}{*}{ Variable } & \multicolumn{6}{|c|}{2012} & \multicolumn{6}{|c|}{2016} \\
\hline & $\begin{array}{l}\text { Mini- } \\
\text { mum } \\
\text { value }\end{array}$ & $\begin{array}{l}\text { Maxi- } \\
\text { mum } \\
\text { value }\end{array}$ & $\begin{array}{c}\text { Aver- } \\
\text { age } \\
\text { value }\end{array}$ & $\begin{array}{c}\text { Upper } \\
\text { quartile }\end{array}$ & Median & $\begin{array}{l}\text { Lower } \\
\text { quartile }\end{array}$ & $\begin{array}{l}\text { Mini- } \\
\text { mum } \\
\text { value }\end{array}$ & $\begin{array}{l}\text { Maxi- } \\
\text { mum } \\
\text { value }\end{array}$ & $\begin{array}{c}\text { Aver- } \\
\text { age } \\
\text { value }\end{array}$ & $\begin{array}{l}\text { Upper } \\
\text { quartile }\end{array}$ & Median & $\begin{array}{l}\text { Lower } \\
\text { quartile }\end{array}$ \\
\hline Intercept & -0.407 & -0.035 & -0.137 & -0.170 & -0.094 & -0.073 & -0.399 & -0.084 & -0.169 & -0.197 & -0.146 & -0.122 \\
\hline$T P$ & 0.658 & 2.896 & 1.307 & 0.798 & 1.083 & 1.655 & 0.420 & 2.985 & 1.055 & 0.571 & 0.867 & 1.306 \\
\hline$P G D P$ & -1.277 & 2.071 & 0.973 & 0.704 & 0.749 & 1.540 & 0.020 & 3.405 & 0.868 & 0.554 & 0.607 & 0.936 \\
\hline$I S$ & -0.052 & 0.244 & 0.032 & -0.020 & 0.007 & 0.060 & -0.040 & 0.345 & 0.071 & 0.026 & 0.047 & 0.094 \\
\hline$T D I$ & -1.110 & 0.052 & -0.145 & -0.144 & -0.095 & -0.058 & -0.377 & 0.088 & -0.074 & -0.107 & -0.062 & -0.022 \\
\hline ETT & 0.150 & 0.621 & 0.327 & 0.210 & 0.293 & 0.429 & 0.171 & 0.486 & 0.275 & 0.227 & 0.252 & 0.302 \\
\hline$U R$ & -0.004 & 0.459 & 0.136 & 0.076 & 0.097 & 0.165 & 0.004 & 0.352 & 0.157 & 0.110 & 0.144 & 0.197 \\
\hline$I A P$ & -0.165 & 0.918 & 0.202 & 0.014 & 0.161 & 0.395 & -0.119 & 0.544 & 0.182 & 0.028 & 0.161 & 0.301 \\
\hline \multirow{2}{*}{$\begin{array}{l}\text { Model } \\
\text { diagnosis }\end{array}$} & \multicolumn{2}{|c|}{ Bandwidth } & \multicolumn{2}{|c|}{ Correction $R^{2}$} & \multicolumn{2}{|c|}{ AIC } & \multicolumn{2}{|c|}{ Bandwidth } & \multicolumn{2}{|c|}{ Correction $R^{2}$} & \multicolumn{2}{|c|}{ AIC } \\
\hline & \multicolumn{2}{|c|}{99877.656} & \multicolumn{2}{|c|}{0.948} & \multicolumn{2}{|c|}{-527.574} & \multicolumn{2}{|c|}{105540.116} & \multicolumn{2}{|c|}{0.900} & \multicolumn{2}{|c|}{-454.605} \\
\hline
\end{tabular}

from 2012, among which Shijiazhuang, Handan, Xingtai, and the other central and southern regions of Hebei Province were significantly affected, while Beijing, Tianjin, and their surrounding areas, Zhangjiakou and Chengde, were less impacted. This means that, against the background of relieving the stress of urban population in Beijing and Tianjin, the central and southern Hebei province, as the main area for undertaking surplus population transfer, still had considerable potential for future population growth. However, in view of the positive coupling effect between population growth and environmental stress in the region, we should be alert to the environmental deterioration caused by excessive population growth and excessive concentration.

(2) The regression coefficient of economic development level was positive over the whole region, and the increase in per capita GDP significantly increased the level of county environmental stress. In addition, the impact of economic development level on county environmental stress decreased from south to north. According to the law of the environmental Kuznets curve, it can be inferred that the central and northern parts of Beijing-Tianjin- Hebei were closer to the inflection point of the inverted U-shaped curve. In terms of the distribution of regression coefficients in 2016, the effect of economic development level decreased in the optimized development zone of central China, which reflected the fact that the development mode of this kind of MFZ gradually changed at the expense of the environment, which alleviated the high levels of environmental stress.

(3) The level of industrialization passed the significance test in 2016, and its action on the level of county environmental stress had spatial differentiation. It was positively driven to the east of Tangshan and Qinhuangdao, but negatively driven in Zhangjiakou and southeast of Handan, which meant that the increase in the proportion of secondary industry was beneficial for alleviating the level of environmental stress. Combined with an analysis of county industrial departments, it was found that heavily polluting industrial enterprises that were strongly driven by county environmental stress (Pearson correlation coefficient $r>0.5$ and significance $p<0.05$ ) could be targeted for technical transformation and upgrading, including nonmetallic mineral products, ferrous metal smelting and rolling processing, petroleum 


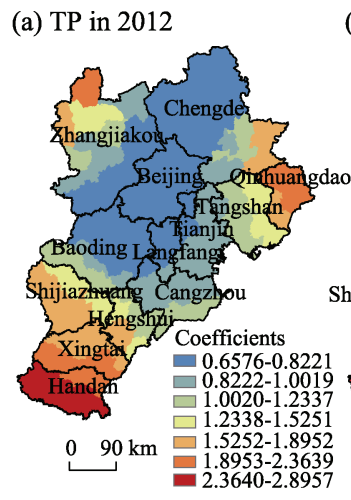

(e) IS in 2012

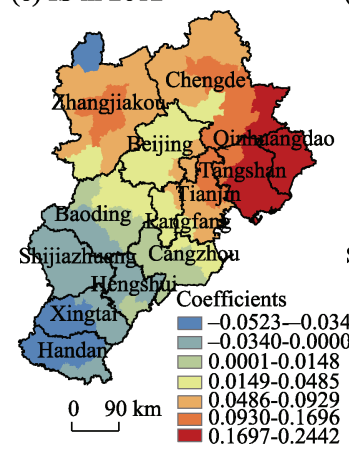

(b) TP in 2016

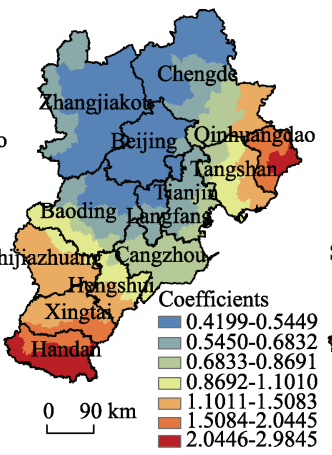

(c) PGDP in 2012

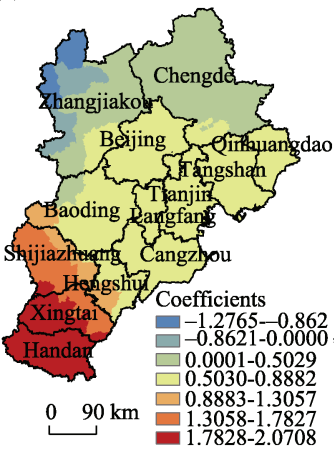

(d) PGDP in 2016

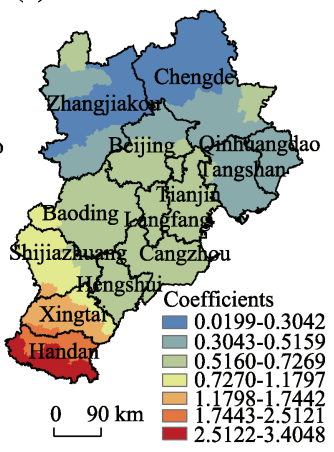

(f) IS in 2016

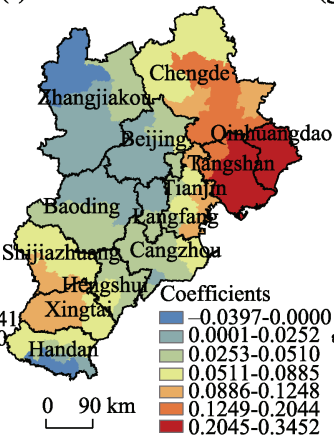

(g) TDI in 2012

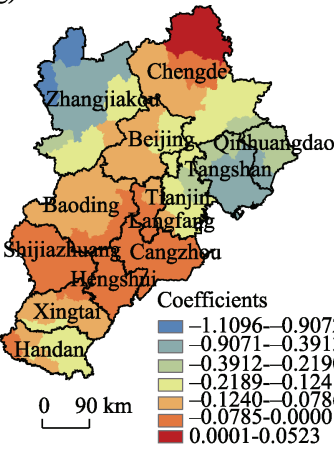

(h) TDI in 2016

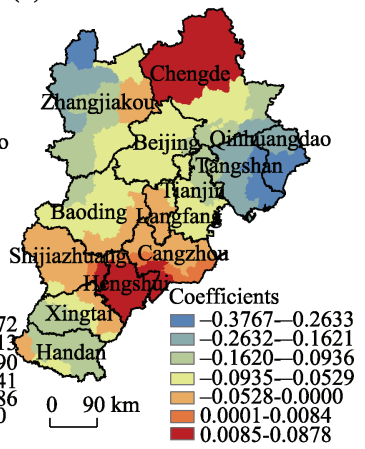

(i) ETT in 2012

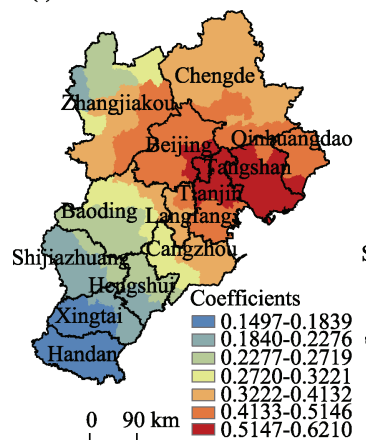

(j) ETT in 2016

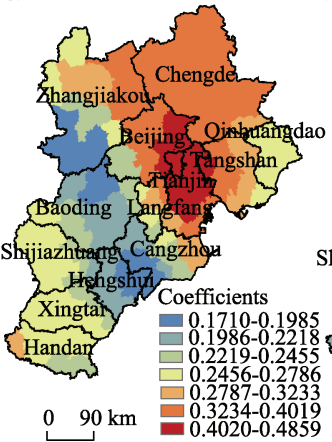

(k) UR in 2012

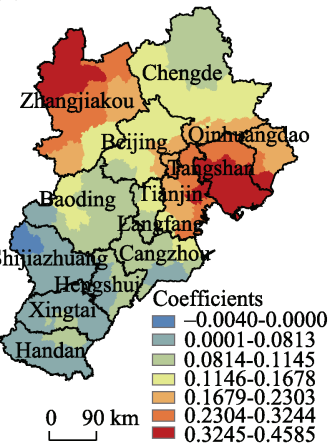

(1) UR in 2016

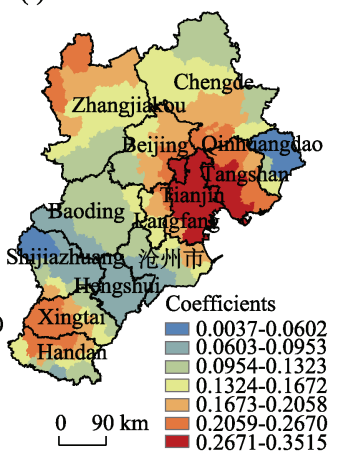

(m) IAP in 2012

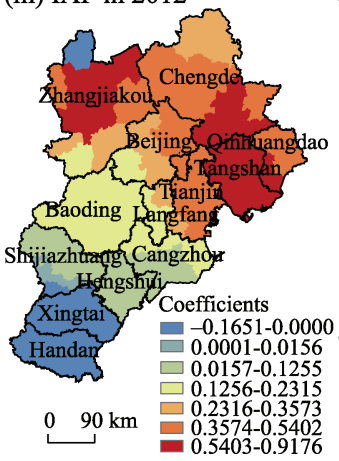

(n) IAP in 2016

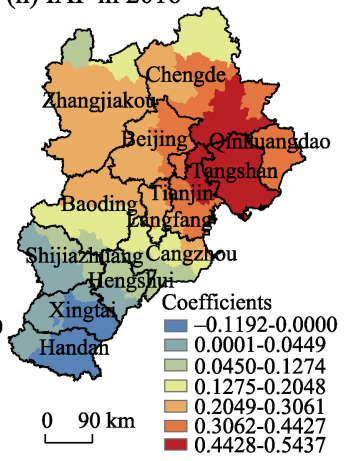

Figure 5 Spatial distribution of regression coefficients in the Beijing-Tianjin-Hebei region 
processing and coking, electrical heating production and supply, coal mining and washing, chemical raw materials and chemical products, metal products, pharmaceuticals manufacturing, and other industry types.

(4) The regression coefficient of land development intensity was mainly negatively driven in 2012, but land development intensity showed a significant positive driving force by 2016 in Hengshui, southern Cangzhou, northern Chengde, and other areas. These indicated that construction land expansion in prioritized development zone began to exert environmental stress, and therefore it was necessary to strengthen the management and control of construction land in order to prevent the spread of pollution caused by urban sprawl, industrial bloom, and excessive dispersion of development zones. In view of the special location of northern Hebei in the "windward landscape" of the Beijing-Tianjin-Hebei region, the land development policy of this kind of key ecological function zone should be moderately tightened to maintain the ecological conservation function and prevent damage to the eco-environment.

(5) The regression coefficient of environmental treatment technology level was positive in the Beijing-Tianjin-Hebei region because the pollution intensity index per unit GDP was used to reflect the level of environmental treatment technology; the larger the index value, the lower the environmental treatment technology level. Therefore, the low level of environmental treatment technology aggravated the level of regional environmental stress, which decreased from the Beijing-Tianjin-Tangshan region to the peripheral areas. In Beijing, Tianjin, and north of that region, the pollution treatment capacity was still finding it difficult to cope with high levels of environmental stress.

(6) The level of urbanization passed the significance test in 2016, and the regression coefficient was positive in the whole of the urban agglomeration. The increase in urbanization rate significantly increased the level of environmental stress in the various counties. During 2012-2016, especially in Tianjin-Tangshan, Xingtai, Zhangjiakou, and other areas around the Bohai Rim, urbanization of the population directly drove high-intensity emissions of pollutants from domestic sources, and this process is an important reason for the increase in the level of environmental stress in the constitutive counties.

(7) The regression coefficient of input intensity of agricultural production was positive over the whole region and decreased from northeast to southwest. Except for south of Handan and Xingtai, the increase in input intensity of agricultural production significantly increased the level of environmental stress in the various counties. This shows that guiding farmers to adopt cleaner modes of production and control agricultural non-point source pollution is very important for alleviating environmental stress in the Beijing-Tianjin-Hebei region.

To sum up, the level of environmental stress in the counties of the Beijing-Tianjin-Hebei region was affected by two controlling factors, namely, population size and economic development level, which presented a differentiated multifactor driving model in four types of regions: The central core functional zone was strongly driven by urbanization and environmental treatment level, and pollution prevention and the control of urban living resources should be the focus of management and control. The total control of pollutant emissions and the assessment of quality standards directly linked with the human settlement environment should be strengthened in these areas, which will drive the transformation of urban produc- 
tion, lifestyles, and consumption patterns.

The coastal development zone in the east is strongly driven by industrialization and urbanization. In view of the industrial structure and high emission characteristics of the zone, it is necessary to highlight the classified management of the environmental access list, reduce the high levels of energy consumption and pollution, restrict the scale of development of energy and heavy chemical industries, and promote decoupling from environmental stress by optimizing the layout of urban both living space and industrial space. The functional development zone in the south is strongly driven by population size, economic development level, and urbanization factors. The supporting environmental infrastructure in the area should be strengthened to relieve the environmental constraints in the comprehensive carrying capacity of the region, and, at the same time, high-quality living environments should enhance the attractiveness of the city to its own population. The ecological conservation zone in the northwest is strongly driven by urbanization and agricultural production input factors. On the basis of the landing of the urban development boundary, the area should highlight the control of pollution sources, improve the disposal and recovery systems for dealing with agriculture-related pollution, encourage the development of eco-agriculture, green agriculture and organic agriculture, and gradually reduce emissions of agricultural non-point source pollutants.

\section{Conclusions and implications}

(1) The level of environmental stress in the Beijing-Tianjin-Hebei region was significantly alleviated during the period 2012-2016. The average decrease in the ESI of the counties in the region was $54.68 \%$ by 2016 , and the level of environmental stress in those counties gradually decreased from the central cities to the peripheries. By 2016, the environmental stress in high-grade counties was eliminated, and the number of high-grade counties decreased from 10 to 6, of which the central cities of Beijing, Tangshan, Tianjin, Shijiazhuang, Handan, and Binhai New Area showed the greatest decreases. The county-scale ESI in Beijing decreased by $63.35 \%$, which was higher than that in Tianjin $(57.75 \%)$ and Hebei $(53.07 \%)$.

(2) The spatial spillover effect of county environmental stress in the region grew stronger during 2012-2016, and the Moran's I value of county-scale ESI increased from 0.2014 in 2012 to 0.2325 in 2016, which showed significant spatial locking and path dependence in the northern coastal area. Further analysis showed that the ESI in the hot spot and sub-hot spot areas of environmental stress decreased by $56.19 \%$ and $44.93 \%$, respectively, which indicates that although the level of environmental stress remained unchanged during that period, the overall mitigation of environmental stress could still be achieved through regional coordinated emission reduction policies and environmental governance.

(3) Urbanized areas (optimized development and prioritized development zones) were the main pressure-bearing areas of pollutant discharge in areas of urban agglomeration, and their level of environmental stress accounted for $65.98 \%$ of the entire Beijing-Tianjin-Hebei region, which remains the key area for environmental pollution prevention and control. Between 2012 and 2016, the ESI of various types of MFZ decreased by more than $50 \%$, the key ecological function zones showing the largest decrease of $56.51 \%$ and the main agricul- 
tural production zones with the smallest decrease of $50.94 \%$.

(4) The OLS model estimated results showed that the significant positive driving factors for county-scale environmental stress during 2012-2016 in the Beijing-Tianjin-Hebei region were population size, economic development level, environmental treatment technology level, agricultural production input intensity, and urbanization level. Of these, county-scale population size and economic development level were the controlling factors for environmental stress, and their intensity decreased. In addition, the goodness of fit of the GWR model was higher than that of the OLS model, and the effects of each factor on county-scale environmental stress were spatially heterogeneous. There were also differentiated multifactor driving modes in the four types of regions: the central core functional zones driven by urbanization and environmental treatment; the eastern coastal development zones driven by industrialization and urbanization; the southern functional expansion zones driven by population size, economic development level, and urbanization; and the northwest ecological conservation zones driven by urbanization and agricultural production input factors. According to the intensity and spatial differences of the various driving factors, differential environmental governance and emission reduction measures at source should be undertaken to significantly improve coordinated environmental control in Beijing, Tianjin, and Hebei.

(5) Based on the county-scale ESI in the Beijing-Tianjin-Hebei region, this paper has analyzed the spatiotemporal patterns of environmental stress and its effect on emission reduction against the background of coordinated development, and constructs an econometric model of driving factors. It discusses the spatial effect of and the factors driving environmental stress at the county level, which provides a reference for formulating coordinated environmental governance policies and reducing the total volume of pollutants emitted. In the future, there are other areas that need to be further studied. For example, studies have shown that non-capital functional relief has significantly improved Beijing's own level of environmental stress, and relevant data (Sha, 2016) show that, since 2014, Beijing has shut down, withdrawn, and transferred 1341 manufacturing enterprises and coal consumption has decreased by $55.19 \%$. For this reason, further studies of the environmental stresses around Beijing and its region, as represented by industrial transfer, need to be undertaken.

Research needs to be strengthened to analyze the effect of county-scale environmental stress from the perspective of industrial departments with different emission intensities and environmental regulation of various types of MFZ in order to study the effect of environmental stress on regional production and lifestyle adjustment and their feedback mechanisms. Due to limitations of county-scale data acquisition, the study period selected for this paper was quite short. In the future, spatiotemporal panel data can be improved on the basis of the second national pollution source census to further study the long-term mechanisms and consequences of environmental stress.

\section{References}

Barrett G W, Vandyne G M, Odum E P, 1976. Stress ecology. Bio-Science, 26(3): 192-194.

Brunsdon C, Fotheringham A S, Charlton M, 1996. Geographically weighted regression: A method for exploring spatial non-stationarity. Geographical Analysis, 28 (4): 281-298.

Chen X, Zhou W Q, Han L J et al., 2016. Spatiotemporal variations of pollutant emissions and their relationship 
with the urbanization of the Beijing-Tianjin-Hebei region agglomeration. Acta Ecologica Sinica, 36(23): 7814-7825. (in Chinese)

Chen Z H, Leizhu J H, 2015. The spatial-temporal characteristics and economic drivers of environmental pollution changes in China. Geographical Research, 34(11): 2165-2178. (in Chinese)

Dinda S, 2004. Environmental Kuznets curve hypothesis: A survey. Ecological Economics, 49(4): 431-455.

Fang C L, 2014. Progress and the future direction of research into urban agglomeration in China. Acta Geographica Sinica, 69(8): 1130-1144. (in Chinese)

Huang L X, Wang H, Song L G, 2012. Is China's industrial change green? Nankai Economic Studies, 164(3): 110-127. (in Chinese)

Kan D X, 2014. Empirical research on the impact of FDI to environmental pollution in China. Research of Environmental Sciences, 27(1): 106-112. (in Chinese)

Lazarus R S, Cohen J B, 1977. Environmental stress. In: Human Behavior and Environment. Springer US, 89-127.

Leeuw F, Moussiopoulos N, Sahm P et al., 2001. Urban air quality in larger conurbations in the European Union. Environmental Modelling \& Software, 16(4): 399-414.

Li H N, Mu H L, Zhang M et al., 2011. Analysis on influence factors of China's $\mathrm{CO}_{2}$ emissions based on Path-STIRPAT model. Energy Policy, 39(11): 6906-6911.

Li J, Zhuang G T, 2011. Features of Environmental Kuznets Curve (EKC) of output of major agricultural pollutants vs economic development level in China. Journal of Ecology and Rural Environment, 27(6): 19-25. (in Chinese)

Li K F, Wang J, 2017. Financial Agglomeration, industrial structure and environmental pollution: Spatial econometric analysis based on China's provinces. Journal of Industrial Technological Economics, 36(3): 3-12. (in Chinese)

Li L G, Zhang P Y, Liu W X et al., 2019. Spatial-temporal evolution characteristics and influencing factors of county-scale environmental pollution in Jilin province, Northeast China. Chinese Journal of Applied Ecology, 30(7): 2361-2370. (in Chinese)

Li L Z, Fu Z Q, Wang Y H et al., 2017. Empirical study on manufacturing transfer and environmental impacts in Jing-Jin-Ji region. Research of Environmental Sciences, 30(12): 1813-1821. (in Chinese)

Liew J, Latif M T, Fredolin T et al., 2009. Spatio-temporal characteristics of $\mathrm{PM}_{10}$ concentration across Malaysia. Atmospheric Environment, 43(30): 4584-4594.

Lin X Q, Wang D, 2016. Spatio-temporal variations and socio-economic driving forces of air quality in Chinese cities. Acta Geographica Sinica, 71(8): 1357-1371. (in Chinese)

Liu H M, Fang C L, Huang J J et al., 2018. The spatial-temporal characteristics and influencing factors of air pollution in Beijing-Tianjin-Hebei region urban agglomeration. Acta Geographica Sinica, 73(1): 177-191. (in Chinese)

Ma L, Kang L, Jin F J, 2018. Spatial and temporal coupling relationship between industrial development and air pollutant emissions in Beijing-Tianjin-Hebei region. Environmental Impact Assessment, 40(5): 43-48. (in Chinese)

Ma S C, Li G Z, 2006. Kuznets curve of the relation between China's economic growth and environmental pollution. Statistical Research, 23(8): 37-40. (in Chinese)

Miao H, Wang X K, Ouyang Z Y. 2001. Study on regionalization of eco-environmental stress process in China. Acta Ecologica Sinica, 21 (1): 7-13. (in Chinese)

Ou X J, Zhen F, Qin Y D et al., 2008. Study on compression level and ideal impetus of regional urbanization: The case of Jiangsu province. Geographical Research, 27(5): 993-1002. (in Chinese)

Pan H F, Wang X, Zhang S Y, 2015. Duration and spatial spillover effects of haze pollution: Evidence from Beijing-Tianjin-Hebei region. China Soft Science, 30(12): 134-143. (in Chinese)

Qu F T, Zhao H X, Zhu D M et al., 2006. Regional difference in pollution and its cause in Jiangsu province. Re- 
sources and Environment in the Yangtze Basin, 15(1): 86-92. (in Chinese)

Rüttenauer T, 2018. Neighbours matter: A nation-wide small-area assessment of environmental inequality in Germany. Social Science Research, 70: 198-211.

Sha L, 2016. 1341 enterprises shut down and quit in Beijing in the past three years. Beijing News, 2016-11-13. (in Chinese)

Shen Y, Zhang L P, Fang X et al., 2019. Spatiotemporal patterns of recent $\mathrm{PM}_{2.5}$ concentrations over typical urban agglomerations in China. Science of the Total Environment, 655: 13-26.

Sui X Y, Wu W, Zhou S L et al., 2015. Drive pattern on the spatial heterogeneity of residential land price in urban district: A comparison of spatial expansion method and GWR model. Scientia Geographica Sinica, 35(6): 683-689. (in Chinese)

Sun K, Xu Z M, Song X Y et al., 2017. Spatial heterogeneity estimation of the impacts of human factors on environmental pollution in Chinese provinces. Acta Ecologica Sinica, 37(8): 2588-2599. (in Chinese)

Wang F, Dong S C, Mao Q L, 2014. Evolution of China's industrial structure and spatial-temporal differentiation in environmental effect. Geographical Research, 33(10): 1793-1806.

Wang Y, Liu H W, Mao G Z et al., 2017. Inter-regional and sectoral linkage analysis of air pollution in Beijing-Tianjin-Hebei (Jing-Jin-Ji) urban agglomeration of China. Journal of Cleaner Production, 165: 1436-1444.

Wei L, Pan A, 2016. Do export and FDI aggravate environmental pollution in resources-based cities? An empirical analysis based on panel data of 285 prefecture cities in China. Journal of Natural Resources, 31(1): 17-27. (in Chinese)

$\mathrm{Xu} \mathrm{H,} \mathrm{Yang} \mathrm{Y,} \mathrm{2017.} \mathrm{Impact} \mathrm{of} \mathrm{population} \mathrm{and} \mathrm{industrial} \mathrm{agglomeration} \mathrm{on} \mathrm{environmental} \mathrm{pollution:} \mathrm{A} \mathrm{case} \mathrm{study}$ of 100 cities in China. Urban Research, 2017(1): 53-60. (in Chinese)

Yan H, Guo Y G, Lin F C, 2010. Analyzing the developing model of Chinese cities under the control of $\mathrm{CO}_{2}$ emissions using the STIRPAT model: A case study of Shanghai. Acta Geographica Sinica, 65(8): 983-990. (in Chinese)

$\mathrm{Yu}$ Y Z, Liu F J, 2017. Impact of spatial agglomeration of productive services on environmental pollution. Research on Financial and Economic Issues, 39(8): 23-29. (in Chinese)

Zhang L, Chen W, Chen X et al., 2011. Space-time Analysis on delinkage between environmental pollution and economic growth in Yangtze River Delta. China Population, Resources and Environment, 21(Suppl.1): 275-279. (in Chinese)

Zheng X X, Li L J, Zhao W J et al., 2014. Spatial and temporal characteristics of atmospheric $\mathrm{NO}_{2}$ in the Beijing-Tianjin-Hebei region. Ecology and Environmental Sciences, 23(12): 1938-1945. (in Chinese)

Zhou K, Fan J, 2016. Regional disparity of environmental pollution source and its socio-economic influencing factors: Based on the cross-section data of 339 cities at prefecture level or above in China. Acta Geographica Sinica, 71(11): 1911-1925. (in Chinese)

Zhou K, Fan J, Liu H C, 2017. Spatiotemporal patterns and driving forces of water pollutant discharge in the Bohai Rim Region. Progress in Geography, 36(2): 171-181. (in Chinese)

Zhou K, Liu H C, Wang Q, 2019. The impact of economic agglomeration on water pollutant emissions from the perspective of spatial spillover effects. Journal of Geographical Sciences, 29(12): 2015-2030.

Zou H, Duan X J, 2016. Pattern evolution of economy-environment coordinated development in the Changjiang River Economic Belt. Scientia Geographica Sinica, 36(9): 1408-1417. (in Chinese) 